\title{
Eksistensi Dakwah Bil Hikmah sebagai Akselerasi Pengembangan Sosial Keagamaan di Kecamatan Sukadana Lampung Timur
}

\author{
Anton Widodo \\ Institut Agama Islam Negeri Metro \\ antonwidodo@metrouniv.ac.id \\ Nur Fauziah Fatawi \\ Institut Agama Islam Negeri Metro \\ nurfauziahfatawi@metrouniv.ac.id \\ Andi Rahmat \\ Institut Agama Islam Negeri Metro \\ rendysalman@gmail.com
}

\begin{abstract}
$D a ' i$ is agents of change who bring ideas and provide innovations for changes in people's lives for the better. As agents of change, many abilities are needed to enable the role of preachers to successfully change society in terms of knowledge, attitudes and behavior, one of which is the ability to convey da'wah messages through tabligh and the ability to communicate. The focus of this research is how $D a$ 'is in Sukadana, East Lampung Regency carry out proselytization and carry out missions as agents of change. This research is a phenomenological study so that the interpretive paradigm uses a phenomenological approach. Research data collection was carried out by observation, documentation and interviews, involving five $D a{ }^{\prime} i$ as research objects. The results showed that the Da' $i$ experience in carrying out dakwah bil hikmah was claimed to have succeeded in bringing about positive changes in the Sukadana community. $D a$ ' $i$ is in Sukadana have outstanding abilities and are successful in their preaching by preaching bil hikmah. Their proselytization is carried out through religious, social guidance and proselytizing activities by providing information and ideas to change the Sukadana community into obedient and devout people to Allah and be accepted by other communities. Da'is in conveying da'wah messages through tabligh in Sukadana District are under informative and educational functions with proselytizing activities through Majlis Taklim, Friday sermons and other non-formal lectures. This finding confirms that the dakwah bil hikmah should continue to be used as an ideal missionary in Islamic society.
\end{abstract}

Keywords: Da'i; proselytization; bil hikmah, social religious; Sukadana

\begin{abstract}
Abstrak
$D a ' i$ merupakan agen perubahan yang membawa ide, gagasan, serta memberikan inovasi bagi perubahan kehidupan masyarakat untuk menjadi lebih baik. Sebagai agen perubahan diperlukan banyak kemampuan agar memungkinkan peran $D a{ }^{\prime} i$ dapat sukses merubah masyarakat dalam hal pengetahuan, sikap dan perilaku, salah satunya kemampuan menyampaikan pesan dakwah melalui tabligh dan kemampuan berkomunikasi. Fokus penelitian ini adalah bagaimana para $D a{ }^{\prime} i$ di Kecamatan Sukadana Kabupaten Lampung Timur melaksanakan dakwah dan menjalankan misi sebagai agen perubahan. Penelitian ini merupakan studi fenomenologis sehingga paradigma interpretatif menggunakan pendekatan fenomenologi. Pengumpulan data penelitian dilakukan dengan observasi, dokumentasi dan wawancara, dengan melibatkan lima orang $D a{ }^{\prime} i$ sebagai objek penelitian. Hasil penelitian menunjukkan bahwa pengalaman $D a{ }^{\prime} i$ dalam melaksanakan dakwah bil hikmah diklaim berhasil menghadirkan perubahan positif pada masyarakat Sukadana. $D a$ ' $i$ di Sukadana memiliki kemampuan yang ideal dan berhasil dalam dakwahnya dengan dakwah bil hikmah. Dakwah mereka lakukan melalui kegiatan pembinaan
\end{abstract}


dan bimbingan sosial keagamaan dengan memberikan informasi dan gagasan untuk merubah masyarakat Sukadana menjadi orang yang taat dan bertaqwa kepada Allah dan diterima oleh masyarakat lainnya. $D a{ }^{\prime} i$ dalam menyampaikan pesan dakwah melalui tabligh di Kecamatan Sukadana sesuai dengan fungsi informatif dan edukatif dengan kegiatan dakwah melalui Majlis Taklim, khutbah Jum'at dan ceramah non-formal lainnya. Temuan ini menegaskan bahwa dakwah bil hikmah semestinya menjadi dakwah ideal dan mainstream di tengah masyarakat Islam.

\section{Kata Kunci: Da’i; dakwah; bil hikmah; sosial keagamaan; Sukadana}

\section{A. Pendahuluan}

Perkembangan ilmu teknologi informasi yang sangat pesat memiliki pengaruh terhadap kebiasaan dan norma yang berlaku di masyarakat. Hal tersebut mengharuskan $D a$ ' $i$ untuk selalu meningkatkan kemampuan dalam penyampaian ajaran agama dalam berbagai aspek seperti materi dakwah, kecerdasan, dan akhlak seorang $D a{ }^{\prime} i$ itu sendiri agar dapat menyampaikan ajaran Agama Islam dengan lebih baik. Ajaran Islam sejatinya disampaikan sebagaimana Rasulullah saw. menuntun dan mengajak melalui "berita gembira" dan "peringatan", seperti disebutkan dalam QS. Saba'/34: 28:

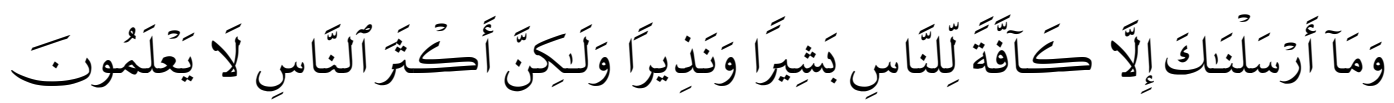

Terjemahnya: dan Kami tidak mengutus kamu, melainkan kepada umat manusia seluruhnya sebagai pembawa berita gembira dan sebagai pemberi peringatan, tetapi kebanyakan manusia tiada mengetahui.

Kabar bahagia dari Rasulullah menggambarkan perilaku serta kedudukan manusia di antara makhluk ciptaan Tuhan yang lain ${ }^{1}$. Manusia adalah ciptaan Allah yang paling sempurna. Hal tersebut merupakan rahmat yang sangat besar. Insan yang dimuliakan Allah lebih dari makhluk yang lainnya, dijadikan khalifah Allah di dunia. ${ }^{2}$ Maksud khalifah atau pengganti bermaksud memberikan tanggung jawab terhadap manusia untuk menjalankan perintah dan tugas hidup didunia. Selain dianugrahkan akal kemampuan secara fisik, manusia juga memiliki hawa nafsu serta rasa yang akan saling berkaitan di semua aktivitas manusia. Hawa nafsu akan cenderung ke hal-hal jahat serta keburukan jika akal serta rasa manusia tak sanggup untuk mengontrolnya. ${ }^{3}$

Prinsip kekhalifahan dan kesempurnaan manusia menuntut adanya tanggung jawab dalam menyeru dalam kebaikan serta menjauhi keburukan ataupun larangan yang dapat merusak citra kesempurnaan tersebut. Tanggungjawab sosial tersebut dalam Islam dikenal dengan tugas dakwah. Dakwah yang ideal adalah seperti yang dicontohkan Nabi Muhammad yang merepresentasikan Islam rahmatan lil 'alamin (rahmat bagi seluruh alam). Konsekuensi kerahmatan Islam adalah terwujdunya kemaslahatan manusia dalam segala bidang.

Dakwah merupakan bagian yang tak terpisahkan dari sejarah dan perjalanan kehidupan umat Islam. Umat muslim bahkan digelari khair ummah yang konsekuensinya adalah kewajiban menyeru dalam kebaikan serta menjauhi kemunkaran, sebagaimana disebutkan QS Ali-Imrān/3: 110:

\footnotetext{
${ }^{1}$ Siti Khasinah, "Hakikat Manusia Menurut Pandangan Islam dan Barat,” Jurnal Ilmiah Didaktika 13, No. 2 (February 1, 2013): 54, Doi:10.22373/Jid.V13i2.480.

${ }^{2}$ Afrida Afrida, "Hakikat Manusia dalam Perspektif Al-Qur`an," Al-Qisthu: Jurnal Kajian Ilmu-ilmu Hukum 16, no. 2 (December 30, 2018): 6, doi:10.32694/010510.

${ }^{3}$ Anton Widodo, "Urgensi Bimbingan Keagamaan Islam Terhadap Pembentukan Keimanan Mualaf," Jurnal Bimbingan Penyuluhan Islam 1, no. 01 (July 2, 2019): 67, doi:10.32332/jbpi.v1i01.1476.
} 


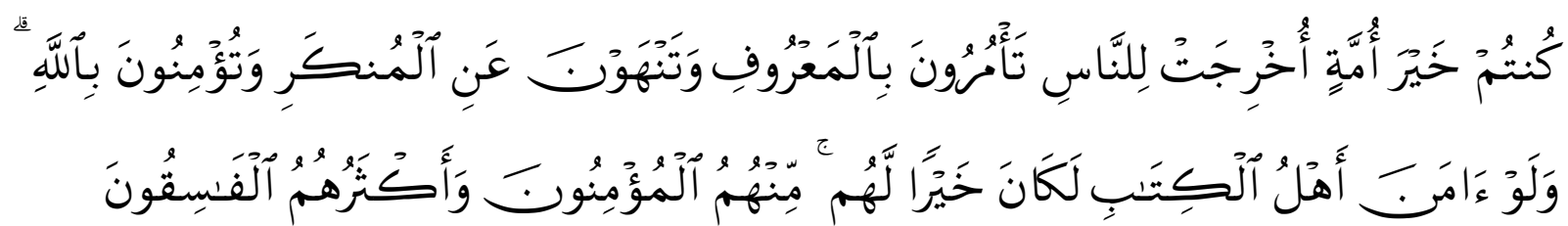

Terjemahnya: kamu adalah umat yang terbaik yang dilahirkan untuk manusia, menyuruh kepada yang ma 'ruf, dan mencegah dari yang munkar, dan beriman kepada Allah. Sekiranya ahli kitab beriman, tentulah itu lebih baik bagi mereka, di antara mereka ada yang beriman, dan kebanyakan mereka adalah orang-orang yang fasik. ${ }^{4}$

Dakwah dapat diartikan dengan melakukan hal yang baik serta menjauhi hal buruk, serta memberi semangat semua orang supaya melakukan hal baik serta ikut dalam arahan agar manusia mendapatkan kebahagian dunia akhirat. ${ }^{5}$ Pelaksanaan seruan ini tak akan berjalan sebagaimana mestinya jika tidak adanya kerja sama yang terstuktur ataupun persiapan dan rancangan yang menggunakan system yang efektif dan efesien, atau hanya dilakukan perorangan saja.

Kegiatan berdakwah juga menuntut $d a{ }^{\prime} i$ mampu memilih cara terbaik dalam menyelesaikan permasalahan yang ada di masyarakat, sebagai objek dakwah yang lebih kompleks. Setelah itu pelaksanaan dakwah harus sesuai dengan penerapan metode yang telah ditentukan. Seorang $d a{ }^{\prime} i$ harus mengerti dan paham keadaan jamaah, selain itu memahami kondisi sekitar serta adat kebudayaan juga menjadi hal yang perlu diperhatikan. Kepentingan berdakwah mengharuskan seorang $d a^{\prime} i$ agar harus memahami cara berfikir jamaahnya. Hal tersebut perlu karena menyampaikan hal tersebut harus memperhatikan kemampuan serap jamaah.

Seorang $d a ' i$ memerlukan cara tertentu dalam penyampaian dakwahnya terhadap mad'u. hal tersebut berarti penyampaian materi dakwah harus berdasar pada human oriented. ${ }^{6}$ Hal tersebut dapat terepresentasi dalam dakwah bil hikmah. M. Abduh berargumen bahwa hikmah merupakan tahu rahasia serta faidah di setiap hal. Hikmah dapat dipakai juga diartikan sebagai menempatkan sesuatu di tempat yang seharusnya. Imam Abdullah bin Ahmad Mahmud al-Nasafi berpendapat dakwah bil hikmah merupakan dakwah menggunakan perkataan yang benar dan pasti, yaitu dalil yang menjelaskan kebenaran dan menghilangkan keraguan ${ }^{7}$. Dakwah bil hikmah adalah kecakapan seorang $d a ' i$ dalam menentukan metode serta cara berdakwah dengan melihat keadaan jamaah serta kemampuan seorang $d a^{\prime} i$ dalam menyampaikan doktrin ajaran Islam dan realitas dengan pendapat yang masuk akal serta bahasa yang mudah dipahami. Metode bil hikmah merupakan cara yang mempersatukan kemampuan teori dan praktik dalam seruan ajaran agama Islam. Oleh karena itu, problem dakwah adalah bagaimana dakwah bil hikmah menjadi cara pengembangan keagamaan dalam kehidupan sosial. $^{8}$

Aktifitas dakwah bil hikmah saat ini masih sangat efektif karena penyampaian pesannya secara langsung disampaikan oleh $d a{ }^{\prime} i$ dengan tema-tema sesuai dengan kebutuhan mad'u

\footnotetext{
${ }^{4}$ Departemen Agama RI Departemen Agama RI, Al-Qur'an dan Terjemahnya (Jakarta, 2010).

${ }^{5}$ Siti Rohmatul Fatihah, “Konsep Etika dalam Dakwah,” Jurnal Ilmu Dakwah 38, no. 2 (July 30, 2019): 246, doi:10.21580/jid.v38.2.3886.

${ }^{6}$ Noormawanti Iswati, “Konsep Diri Seorang Da'i," Jurnal Bimbingan Penyuluhan Islam 1, no. 2 (December 25, 2019): 210, doi:10.32332/jbpi.v1i2.1719.

${ }^{7}$ Junizar Suratman, "Pendekatan Penanfisran al-Qur'an yang Didasarkan pada Instrumen Riwayat, Nalar, dan Isyarat Batin," Intizar 20, no. 1 (2014): 43.

${ }^{8}$ Aliyudin Aliyudin, "Prinsip-Prinsip Metode Dakwah Menurut Al-Quran," Jurnal Ilmu Dakwah 5, no. 16 (November 29, 2014): 1010-11, doi:10.15575/jid.v5i16.360.
} 
(objek dakwah) ${ }^{9}$. Hal itu terjadi pada aktifitas dakwah yang ada di Kecamatan Sukadana Kabupaten Lampung Timur. Metode dakwah bil hikmah masih populer dan di lingkungan tersebut karena pelaksanaan dan isi pesannya bisa masih membuahkan hasil yaitu perubahan positif. ${ }^{10}$ Penduduk transmigrasi dari Pulau Jawa yang terdiri berbagai macam suku, yaitu Sunda, Jawa, dan Lampung, menuntut para $d a{ }^{\prime} i$ untuk lebih kreatif dalam mengemas dan menyampaikan isi pesan dakwah kepada mad'u. Tujuannya adalah untuk meminimalisir gagalnya misi dakwah dan miskomunikasi antara mad'u dan $d a{ }^{\prime} i .{ }^{11}$

Berdasarkan gambaran di atas, penelitian dakwah bil hikmah yang dilakukan oleh $d a{ }^{\prime} i$ sebagai metode penyampai pesan dakwah pada mayarakat Kecamatan Sukadana Kabupaten Lampung Timur dalam aktifitas dakwah yang masih aktif dilakukan oleh $d a$ ' $i$ sangat relevan. Penelitian ini menarik karena pertama, penelitian diharapkan untuk pengembangan dakwah berbasis sosial keagamaan. Kedua untuk lebih memahami pesan komunikasi dakwah yang hendak disampaikan da'i Sukadana melalui kegiatan dakwah yang ada. Ketiga, untuk lebih memahami konstruksi interaksi diantara masyarakat yang plural sehingga memunculkan masyarakat yang toleran.

\section{B. Metode}

Metodologi merupakan suatu implikasi logis, ${ }^{12}$ nilai-nilai, asumsi-asumsi, aturanaturan, dan kriteria yang menjadi bagian tak terpisahkan dalam suatu penelitian. Oleh karena itu, posisi metodologi dipandang sebagai suatu penegas. Paradigma penelitian yang digunakan dalam penelitian ini disesuaikan dengan sifat dan karakter permasalahan data yang diangkat dalam penelitian ini. Oleh karena itu, penelitian ini menggunakan paradigma interpretatif. Menurut Morissan paradigma interpretatif merupakan paradigma yang dilakukan dengan menginterprestasikan karya seni berdasarkan sudut pandang pengamat, baik dari kesamaan pengalaman, unsur estetis, dan pengetahuan yang dimiliki oleh pengamat. Oleh karena itu, penelitian ini fokus pada interaksi, pesan dakwah antara mad'u (masyarakat objek dakwah) dan $d a$ ' $i$ di Kecamatan Sukadana.

Paradigma penelitian menggunakan paradigma interpertatif dan fenomenologi sebagai pisau analisis utamanya. Sehingga semua kegiatan $d a{ }^{\prime} i$ dan mad'u dapat diartikan secara subjektif tentang bagaimana $d a$ ' $i$ menyampaikan pesan dan respon masyarakat selaku mad'u menerima pesan dakwah. Hal tersebut dilakukan karena penelitian ini bertujuan untuk mengetahui secara subjektif bentuk-bentuk komunikasi dari segi pengalaman ${ }^{13}$, penyampaian pesan dakwah dan interaksi $d a{ }^{\prime} i$ dengan masyarakat setempat. Metode penelitian dalam ini akan menggunakan naturalistik, karena penelitian dilakukan pada kondisi yang alamiah (natural setting), penelitian dilakukan pada objek yang alamiah yakni objek yang berkembang apa adanya, tidak dimanipulasi oleh peneliti. ${ }^{14}$ Jenis penelitian ini adalah penelitian kualitatif deskriptif, sehingga data penelitian ini berupa ungkapan dan pernyataan yang selanjutnya dianalisis. Data tersebut diperoleh dengan melalui interview, observasi dan dokumen terkait. ${ }^{15}$

\footnotetext{
${ }^{9}$ Nazirman Nazirman, "Konsep Metode Dakwah Bil Hikmah dan Implementasinya dalam Tabligh,” AlHikmah: Jurnal Dakwah dan Ilmu Komunikasi, June 1, 2018, 31, doi:10.15548/al-hikmah.v0i0.91.

${ }^{10}$ Waryono Abdul Ghafur, "Dakwah Bil-Hikmah di Era Informasi dan Globalisasi," JURNAL ILMU DAKWAH 34 (2014): 237-38.

${ }^{11}$ Anton Widodo, "Urgensi Bimbingan Keagamaan Islam Terhadap Pembentukan Keimanan Mualaf," Jurnal Bimbingan Penyuluhan Islam 1, no. 01 (July 2, 2019): 13, doi:10.32332/jbpi.v1i01.1476.

${ }^{12}$ Nurma Ali Ridlwan, "Pendekatan Fenomenologi dalam Kajian Agama," KOMUNIKA: Jurnal Dakwah dan Komunikasi 7, no. 2 (January 1, 1970): 7, doi:10.24090/komunika.v7i2.385.

${ }^{13}$ Tari Budayanti Usop, "Kajian Literatur Metodologi Penelitian Fenomenologi dan Etnografi," 2019, 10 , doi:10.13140/RG.2.2.15786.47044.

${ }^{14}$ Sugiyono, Metode Penelitian Pendidikan; Pendekatan Kuantitatif, Kualitatif, dan R\&D, III (Bandung: Alfabeta, 2010), 15.

${ }^{15}$ Asmadi Alsa, Penelitian Psikologi, II (Yogyakarta: Pustaka Pelajar Offset, 2004), 12.
} 
Sumber data dalam penelitian ini diperoleh dari para $d a$ ' $i$ dan masyarakat Kecamatan Sukadana yang telah memiliki pengalaman-pengalaman pada saat melakukan malakukan aktifitas dakwah kepada masyarakat. Pada saat kegiatan penelitian berlangsung dalam persoalan ini, yang dilakukan terkait dengan kegiatan ini adalah bertanya, mengamati dan mendengar sehingga, data yang didapatkan murni data pokok sesuai dengan apa yang dibutukan dalam penelitian ini.

\section{Hasil dan Pembahasan}

\section{C.1. Metode Da'i di Kecamatan Sukadana dalam Dakwah Bil Hikmah}

Setiap $d a ' i$ di Kecamatan Sukadana mempunyai pengalaman yang berbeda walaupun bergantung pada tingkat pengetahuan dan pendidikan, faktor obyek atau target yang dipersepsikan dan faktor situasi dimana pengalaman itu dilakukan, umur, tingkat pendidikan, latar belakang sosial ekonomi, budaya, lingkungan fisik, pekerjaan, kepribadian dan pengalaman hidup setiap individu juga ikut menentukan pengalaman.

$D a$ ' $i$ pada umumnya adalah pihak yang memberikan kegiatan dakwah kepada seseorang atau kelompok orang yang sedang mengalami persoalan dalam hidupnya. ${ }^{16}$ Sehingga peran dan tugas $d a$ ' $i$ tidak terbatas pada penyampaian informasi atau pesan dakwah melalui tabligh terkait persoalan keagamaan semata, melainkan memiliki tanggung jawab besar lainnya yaitu tanggung jawab moral dan tanggung jawab sosial untuk melakukan kegiatan yang menyangkut pembelaan terhadap umat atau masyarakat binaannya dari berbagai ancaman, gangguan, hambatan dan bahkan tantangan yang merugikan aqidah, mengganggu ibadah dan merusak akhlak serta stabilitas nasionalisme.

Penyampaian pesan dakwah melalui pengajian $d a$ ' $i$ di Sukadana mengandung unsur psikologi, hal itu penting untuk mengetahui kondisi masyarakat di Kecamatan Sukadana ${ }^{17}$. Para $d a ' i$ menyadari bahwa kegiatan mereka merupakan representasi dari salah satu bentuk kegiatan dakwah sekaligus pendidikan. Kesamaaan konsep antara kedua bentuk kegiatan adalah memiliki dimensi dan tujuan yang sama yaitu menyampaikan pesan dakwah. Kegiatan dakwah dalam literasi bahasa arab memiliki konsep besar yang disebut sebagai al-wad'u atau masyarakat menyebutnya dengan istilah tausyiah atau taujih.

Penyampaian pesan dakwah melalui tabligh yang dilakukan $d a$ ' $i$ dalam membina masyarakat Kecamatan Sukadana dapat ditinjau dari beberapa aspek di antaranya: pertama, ditinjau dari bentuk kegiatan yang dilakukan oleh para $d a$ ' $i$ baik dari Kementerian Agama Kecamatan Sukadana, juga menyampaikan dakwah sesuai dengan fungsi informatif dan edukatif. Bentuk kegiatan dakwah yang dilakukan terdiri dari Majlis Taklim, menyampaikan Khutbah Jum'at dan Ceramah lainnya. Kedua, ditinjau dari jenis pesan yang disampaikan sesuai dengan bentuk kegiatan dakwah yang dilakukan. Jenis-jenis pesan yang disampaikan dalam kegiatan menyampaikan pesan dakwah melalui tabligh ini diantaranya pesan Akidah, Akhlak, Fiqih, dan Cinta Tanah Air atau Nasionalisme. Ketiga, ditinjau dari media yang digunakan dalam menyampaikan pesan dakwah dalam kegiatan kegiatan dakwah, terdiri dari media cetak, media tulis dan media elektronik. Media ceta terdiri dari al-Qur'an, Kitab-kitab Hadits, Buku-buku keagamaan dan media cetak lainnya seperti selembaran atau brosur. Adapun media tulis yang digunakan terdiri dari papan tulis. Sedangkan media elektronik terdiri dari laptop dan proyektor. Keempat, jika ditinjau dari bentuk komunikasi dakwah yang digunakan dalam kegiatan kegiatan dakwah sesuai fungsi informatif dan edukatif terdiri dari komunikasi personal, komunikasi kelompok dan komunikasi massa.

${ }^{16}$ Lalu Ahmad Zaenuri, “Eksistensi Da’i dalam Tilikan Al-Quran” 11, no. 2 (2014): 294.

${ }^{17}$ Agus Salim, "Peran Dan Fungsi Dai Dalam Perspektif Psikologi Dakwah," AL-HIKMAH: Media Dakwah, Komunikasi, Sosial dan Budaya 8, no. 1 (April 22, 2018): 12, doi:10.32505/hikmah.v8i1.401. 


\section{C.2. Fungsi $\mathrm{Da}$ 'i dalam Interaksi dengan $\mathrm{Mad}^{\prime} \overline{\boldsymbol{u}}$ di Kecamatan Sukadana}

Kegiatan kegiatan dakwah pada hakikatnya merupakan serangkaian bentuk kegiatan yang menggambarkan proses interaksi komunikasi antara $d a^{\prime} i$ dengan masyarakat binaannya. Selanjutnya serangkaian bentuk interaksi inilah yang disebut Komunikasi Dakwah. Kegiatan $d a$ ' $i$ dalam kaitannya dengan binaan masyarakat Kecamatan Sukadana sangat aktif. Interaksi $d a$ ' $i$ dan mad'u di Kecamatan Sukadana dalam kegiatan-kegiatan dakwah menjalankan fungsi konsultatif.

Beberapa bentuk interaksi kegiatan-kegiatan dakwah yaitu silaturahmi. Sedangkan pesan yang disampaikan dalam kegiatan bimbingan dan konseling tidak terlepas dari empat aspek yaitu, akidah, syariah, fiqih dan muamalah. Media yang digunakan dalam berinteraksi dalam kegiatan dakwah bersifat langsung, karena komunikasi yang digunakan juga sifatnya personal, kecuali kegiatan yang bersifat kelompok yaitu konsultasi di Kantor Urusan Agama, masjid dan tempat pertemuan lainnya.

Dalam berinteraksi dengan masyarakat, $d a$ ' $i$ Sukadana menjalankan fungsi konsultatif, yang merupakan rangkaian dakwah mereka. Para $d a ' i$ menjalankan fungsi sebagai konselor (orang yang mamberikan konsultasi) karena dalam dakwah mereka menyampaikan informasi lain yang dibutuhkan masyarakat. Konsultasi yang mereka lakukan khas konsultasi $d a^{\prime} i$ berbeda dengan konsultasi lainnya. Hal ini sejalan dengan konsep yang dikemukakan Muhammad Rozikan bahwa konsultasi dalam aktifitas dakwah dengan kegiatan konsultasi lainnya adalah pada dimensi substansi isi, proses kegiatan dan pihak yang menjadi konselornya. ${ }^{18}$ Dimensi isi terkait sosial keagamaan sangat kental dalam interaksi dakwah yang dilakukan para $d a{ }^{\prime} i$.

\section{Penutup}

Para $d a$ 'i di Kecamatan Sukadana menunaikan tugas dakwah bil hikmah dengan bertanggungjawab. Prinsip dakwah yang ideal dari Rasulullah dijalankan dengan baik di tengah masyarakat sehingga menunjukkan hasil yang signifikan di tengah masyarakat. Meski para da'i memiliki ragam pengalaman berbeda dalam menyampaikan materi dakwahnya, pada dasarnya mereka melakukan dakwah dengan komprehensif yaitu menyampaikan materi terkait keagamaan seperti akidah, syariah, fikih, dan muamalah dengan penuh hikmah. Di samping itu, $d a$ ' $i$ berhasil berinteraksi dan menjalankan fungsi konsultatif terhadap para objek dakwahnya dengan aktif berkonsultasi dan diskusi dengan jamaah terkait aspek sosial keagamaan lainnya. Oleh karena itu, para $d a^{\prime} i$ di Kecamatan Sukadana dapat diklaim sempurna dalam memenuhi misi dakwah yang informatif, edukatif, konsultatif dalam menyampaikan pesan dakwah melalui tabligh dengan berbagai media, baik media lisan, media cetak, maupun media elektronik.

\section{DAFTAR PUSTAKA}

Afrida, Afrida. "Hakikat Manusia dalam Perspektif Al-Qur`an." Al-Qisthu: Jurnal Kajian Ilmuilmu Hukum 16, no. 2 (December 30, 2018): 54. doi:10.32694/010510.

Aliyudin, Aliyudin. "Prinsip-Prinsip Metode Dakwah Menurut Al-Quran." Jurnal Ilmu Dakwah 5, no. 16 (November 29, 2014): 181. doi:10.15575/jid.v5i16.360.

Alsa, Asmadi. Penelitian Psikologi. II. Yogyakarta: Pustaka Pelajar Offset, 2004.

Departemen Agama RI, Departemen Agama RI. Al-Qur'an dan Terjemahnya. Jakarta, 2010.

Fatihah, Siti Rohmatul. "Konsep Etika dalam Dakwah” Jurnal Ilmu Dakwah 38, no. 2 (July 30, 2019): 241. doi:10.21580/jid.v38.2.3886.

Ghafur, Waryono Abdul. "Dakwah Bil-Hikmah di Era Informasi dan Globalisasi.” Jurnal Ilmu Dakwah 34 (2014): 23.

\footnotetext{
${ }^{18}$ Muhamad Rozikan, "Transformasi Dakwah Melalui Konseling Islami," INJECT (Interdisciplinary Journal of Communication) 2, no. 1 (January 10, 2018): 84-55, doi:10.18326/inject.v2i1.77-98.
} 
Iswati, Noormawanti. “Konsep Diri Seorang Da 'i.” Jurnal Bimbingan Penyuluhan Islam 1, no. 2 (December 25, 2019): 207. doi:10.32332/jbpi.v1i2.1719.

Khasinah, Siti. "Hakikat Manusia Menurut Pandangan Islam dan Barat." Jurnal Ilmiah Didaktika 13, no. 2 (February 1, 2013). doi:10.22373/jid.v13i2.480.

Nazirman, Nazirman. "Konsep Metode Dakwah Bil Hikmah dan Implementasinya dalam Tabligh." Al-Hikmah: Jurnal Dakwah dan Ilmu Komunikasi, June 1, 2018, 31-41. doi:10.15548/al-hikmah.v0i0.91.

"Paradigma Interpretatif.Htm," n.d.

Rasyid, Muhammad Makmun. "Islam Rahmatan Lil Alamin Perspektif KH. Hasyim Muzadi." Epistemé: Jurnal Pengembangan Ilmu Keislaman 11, no. 1 (June 1, 2016): 93-116. doi:10.21274/epis.2016.11.1.93-116.

Razak, Yusran. Sosiologi Sebuah Pengantar: Tinjauan Pemikiran Sosiologi Perspektif Islam. Jakarta: Laboratoruim Sosiologi Agama, n.d.

Ridlwan, Nurma Ali. "Pendekatan Fenomenologi dalam Kajian Agama." KOMUNIKA: Jurnal Dakwah dan Komunikasi 7, no. 2 (January 1, 1970). doi:10.24090/komunika.v7i2.385.

Rozikan, Muhamad. "Transformasi Dakwah Melalui Konseling Islami." INJECT (Interdisciplinary Journal of Communication) 2, no. 1 (January 10, 2018): 77. doi:10.18326/inject.v2i1.77-98.

Salim, Agus. "Peran dan Fungsi Dai Dalam Perspektif Psikologi Dakwah." AL-HIKMAH: Media Dakwah, Komunikasi, Sosial dan Budaya 8, no. 1 (April 22, 2018). doi:10.32505/hikmah.v8i1.401.

Sugiyono. Metode Penelitian Pendidikan; Pendekatan Kuantitatif, Kualitatif, Dan R\&D. III. Bandung: Alfabeta, 2010.

Suratman, Junizar. "Pendekatan Penanfisran al-Qur'an yang Didasarkan pada Instrumen Riwayat, Nalar, dan Isyarat Batin.” Intizar 20, no. 1 (2014): 20.

Tari Budayanti Usop. "Kajian Literatur Metodologi Penelitian Fenomenologi dan Etnografi," 2019. doi:10.13140/RG.2.2.15786.47044.

Widodo, Anton. "Urgensi Bimbingan Keagamaan Islam Terhadap Pembentukan Keimanan Mualaf." Jurnal Bimbingan Penyuluhan Islam 1, no. 01 (July 2, 2019): 66. doi:10.32332/jbpi.v1i01.1476.

Zaenuri, Lalu Ahmad. “Eksistensi Da’i dalam Tilikan Al-Qur'an” 11, no. 2 (2014): 22. 